\title{
Virulence and Other Biological Properties of Salmonella Typhimurium Isolated from Foals in Japan from 1981 until 1996
}

\author{
Toru ANZAI $^{1 *}$, Yasushi KUWAMOTO ${ }^{1}$, Ryuichi WADA ${ }^{1}$, Masato AKIBA $^{2}$, Tats uo OHYA ${ }^{2}$ and \\ Toshiya SAMESHIMA ${ }^{3}$ \\ ${ }^{1}$ Epizootic Research Station, Equine Research Institute, Japan Racing Association, 1400-4 Shiba, \\ Kokubunji-machi, Shimotsuga-gun, Tochigi 329-0412, ${ }^{2}$ Laboratory of Clinical Microbiology, Kyushu Research \\ Station, National Institute of Animal Health, 2702 Chuzan-cho, Kagoshima-shi, Kagoshima 891-0105, \\ ${ }^{3}$ Laboratory of Zoonosis, Feed Research Division, National Institute of Animal Health, Kannondai 3-1-1, \\ Tsukuba, Ibaraki 305-0856, Japan
}

\begin{abstract}
Sixteen strains of Salmonella enterica serotype Typhimurium (S. Typhimurium) isolated from foals from 1981 until 1996 in Hokkaido Prefecture, Japan, were examined for their biotype, drug resistance, plasmid profile, virulence plasmid, and virulence in mice and foals. Nine strains isolated from Thoroughbred foals in Hidaka district in 1981 were shown to possess similar properties. Likewise, two strains isolated from crossbred foals in a farm in Sorachi district in 1996, although distinct from the Hidaka isolates, were similar to one another. These 11 strains were all shown to contain a virulence plasmid, and to be virulent in mice and foals. However, five other strains isolated from Thoroughbred foals that were bred in different farms in Hidaka between 1990 and 1993 demonstrated variable properties, and did not possess the virulence plasmid nor show virulence in mice. Thus it was suggested that large outbreaks of S. Typhimurium infection in foals were more likely to be caused by virulent strains possessing the virulence plasmid, although sporadic infections may also be caused by non-virulent $S$. Typhimurium.
\end{abstract}

Key words: foal, Salmonella Typhimurium, virulence plasmid

Salmonella enterica serotype Typhimurium ( $S$. Typhimurium), is a facultative anaerobic gram-negative medium-sized rod belonging to the family Enterobacteriaceae. S. Typimurium is frequently associated with disease in a number of animal species, including humans, livestock, domestic fowl, rodents and birds, and diarrhea or septicemia caused by $S$. Typhimurium has been reported as an epidemic disease in cows to which significant economic loss has been attributed [13]. S. Typhimurium infection in horses has also been reported in U.S.A., Canada, Netherlands and Japan [4-8, 11, 16-19]. However, compared with that of other domestic animals, the epizootiological background of $S$. Typhimurium is not well understood.

This article was accepted August 12, 2003

*Corresponding author.
J. Equine Sci.

Vol. 14, No. 3

pp. 87-92, 2003
In 1981, $S$. Typhimurium infection was prevalent among Thoroughbred foals in the Hidaka district of Hokkaido, the main racing horse breeding area of Japan [11]. Since that time, $S$. Typhimurium has been isolated from clinical samples from infected foals in this and other areas. In this study, virulence and other biological properties of archived $S$. Typhimurium strains kept at $-80^{\circ} \mathrm{C}$ were examined. Also, recent $S$. Typhimurium infections in Japan were discussed.

\section{Materials and Methods}

\section{Bacteria}

$S$. Typhimurium were isolated from clinical specimens taken from horses between 1981 and 1996 in Hokkaido Prefecture, the main horse breeding area of 
Table 1. Primary biotype and drug resistance of Salmonella Typhimurium isolated from foals

\begin{tabular}{|c|c|c|c|c|}
\hline Strain & Year of isolation & Location, Animals, Source & Primary biotype $^{3)}$ & Drug resistance pattern ${ }^{4)}$ \\
\hline ST-1 & $1981^{1)}$ & Hidaka, Thoroughbred foal, Diarrhoea & 26 & $\mathrm{ABPC}, \mathrm{SM}, \mathrm{KM}, \mathrm{TC}$ \\
\hline ST-2 & 1981 & Hidaka, Thoroughbred foal, Diarrhoea & 26 & $\mathrm{ABPC}, \mathrm{SM}, \mathrm{KM}, \mathrm{TC}$ \\
\hline ST-3 & 1981 & Hidaka, Thoroughbred foal, Diarrhoea & 26 & $\mathrm{ABPC},(\mathrm{SM})^{5)}, \mathrm{TC}$ \\
\hline ST-4 & 1981 & Hidaka, Thoroughbred foal, Diarrhoea & 26 & ABPC, SM, KM, TC \\
\hline ST-5 & 1981 & Hidaka, Thoroughbred foal, Diarrhoea & 26 & ABPC, $(\mathrm{SM}), \mathrm{TC}$ \\
\hline ST-6 & 1981 & Hidaka, Thoroughbred foal, Diarrhoea & 26 & $\mathrm{ABPC},(\mathrm{SM}), \mathrm{TC}$ \\
\hline ST-7 & 1981 & Hidaka, Thoroughbred foal, Diarrhoea & 26 & ABPC, SM, KM, TC \\
\hline ST-8 & 1981 & Hidaka, Thoroughbred foal, Diarrhoea & 26 & $\mathrm{ABPC}, \mathrm{SM}, \mathrm{KM}, \mathrm{TC}$ \\
\hline ST-9 & 1981 & Hidaka, Thoroughbred foal, Diarrhoea & 26 & $\mathrm{ABPC},(\mathrm{SM}), \mathrm{TC}$ \\
\hline ST-11 & 1990 & Hidaka, Thoroughbred foal, Arthritis & 1 & ABPC, SM, TC, FOM, CP \\
\hline ST-12 & 1991 & Hidaka, Thoroughbred foal, Diarrhoea & 1 & ABPC, SM, TC, CP \\
\hline ST-13 & 1991 & Hidaka, Thoroughbred foal, Diarrhoea & 1 & ABPC, SM, TC, FOM, CP \\
\hline ST-14 & 1993 & Hidaka, Thoroughbred foal, Diarrhoea & 1 & FOM \\
\hline ST-15 & 1993 & Hidaka, Thoroughbred foal, Diarrhoea & 1 & ABPC, SM, TC, FOM, CP \\
\hline Sal-7 ${ }^{2)}$ & 1996 & Sorachi, Cross bred foal, Diarrhoea & 2 & $\mathrm{ABPC},(\mathrm{SM}),(\mathrm{TC}), \mathrm{CP}$ \\
\hline Sal-8 & 1996 & Sorachi, Cross bred foal, Diarrhoea & 2 & $\mathrm{ABPC},(\mathrm{SM}),(\mathrm{TC}), \mathrm{CP}$ \\
\hline SST-1 & Reference strain & Chickin & & \\
\hline
\end{tabular}

1) S. Typhimurium infection was prevalent among Thoroughbred foals in Hidaka during this year. 2) Sal-7 and Sal-8 were isolated from a herd infection at a farm in Sorach. 3) Primary biotype 1 is positive for testing with D-xylose, meso-inositol, L-rahmnose, dtartrate and m-tartrate. Biotype 2 is positive for testing with D-xylose, meso-inositol, L-rahmnose and d-tartrate. Biotype 26 is positive for testing with L-rahmnose and d-tartrate. 4) Abbreviations are shown in materials and methods. 5) Parentheses indicate those drugs to which the isolates were slightly resistant.

Japan (Table1). Biochemical properties of bacteria were examined by API 20E (bioMerieux-Vitec Japan, Tokyo) and bacteria were serotyped using antisera against Salmonella (Denka Seiken, Tokyo). A total of 16 strains of $S$. Typhimurium were stored at $-80^{\circ} \mathrm{C}$ until testing. S. Typhimurium SST-1, which was isolated from a fowl and harbored only a virulence plasmid, was used as a reference strain [1].

\section{Biological test}

Primary biotyping of strains was performed as described by Duguid et al. [3] by fermentation testing with D-xylose in Bitter's medium, meso-inositol in peptone water and L-rhamnose in peptone water. In addition, $d$-tartrate turbidity test and m-tartrate plate test were also performed.

\section{Drug susceptibility test}

Antibiotic resistance testing was done using the single disk method (Nissui, Tokyo). Isolates were tested on Modified Mueller-Hinton agar (Nissui) against six antibiotics [Ampicillin (ABPC), Streptomycin (SM), Kanamycine (KM), Tetracycline (TC), Fosfomycine (FOM) and Chloramphenicol (CP)] that were effective against native $S$. Typhimurium. Drug susceptibilities were classified as,,-+++ or +++ according to the manufacturer's recommendation, and were determined to be resistant based on susceptibility classifications of - or + .

\section{Isolation and analysis of plasmid DNA}

Plasmid DNAs were isolated by the method of Kado and Liu [10]. Electrophoretic analysis of isolated plasmid DNAs was performed in $0.8 \%$ agarose (Takara Shuzo, Shiga) and TBE buffer [ $89 \mathrm{mM}$ Tris, $89 \mathrm{mM}$ boric acid, 2 mM EDTA (pH8.3)]. For restriction endonuclease cleavage analysis, plasmid DNAs were isolated by the method of Birnboim and Doly [2] followed by phenol-chloroform extraction. Plasmid DNAs were then digested with restriction endonuclease Sal 1 (Takara Shuzo) and separated by electrophoresis in $0.8 \%$ agarose gel and TBE buffer.

\section{PCR for spvC gene detection}

Detection of the $s p v C$ gene was performed according to the method of Rexach et al. [15]. Briefly, spvC gene specific oligonucleotides, VIR 113 (TTG TAG CTG CTT ATG ATG GGG CGG) and VIR 561 (TGG AGA AAC GAC GCA CTG TAC TGC), were used as primers to amplify a 472bp DNA fragment. PCR amplification 
was carried out using a GeneAmp PCR system 9600 (Perkin Elmer, CT, USA) and electrophoresis of PCR product was performed in $2 \%$ agarose and TBE buffer.

\section{Mouse virulence test}

This test was carried out since it was approved in animal experiment committee of the research station. Overnight bacterial cultures of nine strains were diluted 100-fold in Heart infusion broth (BD Difco, USA) and incubated for a further $5 \mathrm{~h}$ at $37^{\circ} \mathrm{C}$ with rotation. Bacterial cells were then harvested by centrifugation, resuspended and 10-fold serially diluted in physiological saline solution. A volume of $0.1 \mathrm{ml}$ of each serial dilution was injected intraperitoneally into four-week-old IVCS mice (Institute for animal reproduction, Ibaraki). Mice were observed for 7 days following infection. The $50 \%$ lethal dose $\left(\mathrm{LD}_{50}\right)$ of each strain was calculated by the method of Reed and Muench [14].

\section{Experimental infection of horses}

This experiment also done with the approval of animal experiment committee. A latex tube was inserted transnasally into the esophagus of six-monthold Thoroughbred foals who had been fasted for $24 \mathrm{~h}$ and sedated with $1 \mathrm{mg} / \mathrm{kg}$ xylazine. A volume of $100 \mathrm{ml}$ of the same logarithmic culture as used for mouse infection was inoculated into the stomach of the foal through the latex tube which was immediately followed by $250 \mathrm{ml}$ of $10 \%$ sodium bicarbonate. Three foals were inoculated with $1.9 \times 10^{11} \mathrm{CFU}$ of strain ST-1, while another three foals were inoculated with $1.1 \times$ $10^{11}$ CFU of strain SST-1. Surviving foals were euthanized by intravenous injection of a mixture of sodium thiopental (Tanabe Pharmaceutical, Osaka) and suxamethonium chloride (Yamanouchi Pharmaceutical, Osaka) at 36 days post-inoculation. Bacterial isolation was performed using DHL agar (Nissui) at post mortem examination.

\section{Results}

\section{Biotype, drug resistance and plasmid profile}

Sixteen strains of $S$. Typhimurium were classified into 3 groups based on primary biotyping method of Duguit et al [3]. As shown in Table 1, nine strains [ST1, ST-2, ST-3, ST-4, ST-5, ST-6, ST-7, ST-8 and ST-9] that were isolated in 1981 were classified as biotype 26. Five

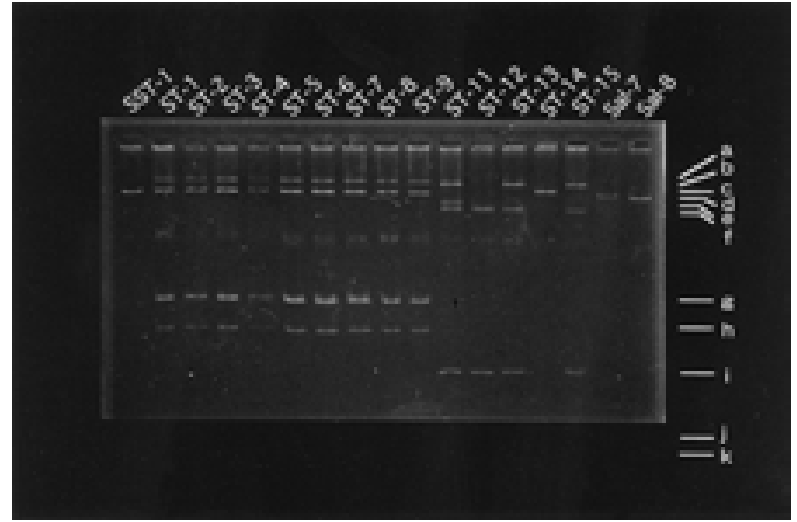

Fig. 1. Plasmid profiles of Salmonella Typhimurium SST-1 and isolates from foals. Letters on the right side of the figure indicate plasmids of different sizes. The bands of smaller plasmids $\mathrm{j}$ and $\mathrm{k}$ were not shown in this figure. Plasmids in each strain were as follows: SST-1; d, ST-1, ST-2, ST-3, ST4, ST-5, ST-6, ST-7, ST-8, ST-9; a,d,g,h, ST-11; b,e,f,I, ST-12; f,I, ST-13, ST-15; b,f,I, ST-14; c, Sal-7; d,j,k, Sal-8; d,k.

strains [ST-11, ST-12, ST-13, ST-14 and ST-15] that were isolated from 1990 until 1993 were biotype 1, while two 2 strains [Sal-7 and Sal-8] that were isolated at Sorachi in 1996 were biotype 2 .

All 16 strains were resistant to some of the six antibiotics tested. As shown in Table 1, five of nine strains [ST-1, ST-2, ST-4, ST-7 and ST-8] isolated in 1981 were resistant to ABPC, SM, KM and TC, while the remaining 4 strains [ST-3, ST-5, ST-6 and ST-9] showed resistance to ABPC, SM (slightly) and TC. Among strains isolated from 1990 until 1993, ST-11, ST-13 and ST-15 were resistant to ABPC, SM, TC, FOM and CP; ST-12 was resistant to ABPC, SM, TC and CP; and ST-14 was resistant to FOM. Both strains isolated in 1996 [Sal7 and Sal-8] were resistant to ABPC, SM (slightly), TC (slightly) and CP.

All 16 strains possessed plasmids of various sizes as shown in Figure 1. Nine strains [ST-1, ST-2, ST-3, ST-4, ST-5, ST-6, ST-7, ST-8 and ST-9] isolated in 1981 harbored 4 kind of plasmids with same profile. Other strains except ST-13 and ST-15 harbored from 1 kind to 4 kinds of plasmid with different profile each other. ST-13 and ST-15 harbored 3 plasmids with same size.

\section{Virulence plasmid and virulence in mice}

Eleven of sixteen strains [ST-1, ST-2, ST-3, ST-4, ST-5, ST-6, ST-7, ST-8, ST-9, Sal-7 and Sal-8] were found to contain plasmids equal in size to that of SST-1 (Table 2) 
Table 2. Virulence plasmid and virulence in mice of Salmonella Typhimurium isolated from foals

\begin{tabular}{|c|c|c|c|c|c|}
\hline \multirow[t]{2}{*}{ Strain } & \multirow[t]{2}{*}{ Year of isolation } & \multicolumn{3}{|c|}{ Virulence-associated plasmid } & \multirow[t]{2}{*}{ Virulence in mice $\left(\mathrm{LD}_{50}\right)^{3)}$} \\
\hline & & $\overline{90 \mathrm{~kb} \text { plasmid }}$ & $\begin{array}{l}\text { Virulence plasmid } \\
\text { restriction profile }\end{array}$ & $s p v C^{(2)}$ & \\
\hline ST-1 & 1981 & + & + & + & 7 \\
\hline ST-2 & 1981 & + & + & + & $\mathrm{NT}^{4)}$ \\
\hline ST-3 & 1981 & + & + & + & 10 \\
\hline ST-4 & 1981 & + & + & + & NT \\
\hline ST-5 & 1981 & + & + & + & NT \\
\hline ST-6 & 1981 & + & + & + & NT \\
\hline ST-7 & 1981 & + & + & + & NT \\
\hline ST-8 & 1981 & + & + & + & NT \\
\hline ST-9 & 1981 & + & + & + & NT \\
\hline ST-11 & 1990 & - & - & - & 3,000 \\
\hline ST-12 & 1991 & - & - & - & 14,000 \\
\hline ST-13 & 1991 & - & - & - & 5,100 \\
\hline ST-14 & 1993 & - & - & - & NT \\
\hline ST-15 & 1993 & - & - & - & $8,500 \leq$ \\
\hline Sal-7 & 1996 & + & + & + & 14 \\
\hline Sal-8 & 1996 & + & + & + & 3 \\
\hline SST-1 & Reference strain & + & + & + & 95,000 \\
\hline
\end{tabular}

1) +: Restriction fragment profiles similar to that of VP of SST-1 following digestion by Sall, - : different to SST-1. 2) +: spvC gene was detected by PCR, -: not detected. 3) Cell suspensions in $0.1 \mathrm{ml}$ saline were injected intraperitoneally into four-week-old IVCS mice. $\mathrm{LD}_{50}$ was calculated at 7 days after injection. 4) NT: Not tested

which all demonstrated similar restriction fragment profiles following digestion with Sall. Also, a 472 bp product originated from $S p v C$ gene was amplified by PCR from the 11 strains and SST-1 but not from the other 5 strains [ST-11, ST-12, ST-13, ST-14 and ST-15]. Examination of virulence in mice revealed that the $\mathrm{LD}_{50}$ of strains ST-11, ST-12, ST-13 and ST-15 ranged about 200-4,000 times higher than that of ST-1, ST-3, Sal-7 and Sal-8. The $\mathrm{LD}_{50}$ of SST-1 was shown to be similar to, or higher than, that observed among strains that did not contain plasmid.

\section{Virulence in foals}

Three foals inoculated with ST-1 died within 1 or 2 days after bacterial inoculation, and high numbers of $S$. Typhimurium were isolated at post mortem examination. Three foals inoculated with SST-1 demonstrated fever for 3 days following bacterial inoculation, and then recovered quickly. $S$. Typhimurium was not isolated from any samples at post mortem examination at 36 days post-inoculation.

\section{Discussion}

Hidaka Prefecture of Hokkaido is the main Thoroughbred breeding area in Japan. Following heavy rains and flooding in this area in the summer of 1981, S. Typhimurium infection spread among Thoroughbred foals. Reasons for the prevalence of $S$. Typhimurium during this year are not clear, but abnormal weather may have had an influence. Kikuchi et al. [11] isolated $S$. Typhimurium from the feces of eight of eleven diseased foals (one of which died) at two Thoroughbred breeding farms in Hidaka during this year. All isolates were described to be the same biotype (26) and phage-type (1/19/23/29/31/36/48). Nine strains examined in this study were also isolated in Hidaka in 1981 and were also all shown to be biotype 26. Additionally, plasmid profiles of these nine strains were consistent and their drug resistance profiles included only two patterns which were similar. Thus, it was suggested that a single strain of $S$. Typhimurium was prevalent among the Thoroughbred-breeding farms in Hidaka in 1981.

Sal-7 and Sal-8 were isolated from crossbred foals during a herd infection at a farm in Sorachi district in 
1996. The biotype and the drug resistance patterns of both the strains were the same, and the plasmid profiles of each were similar. However, these properties were different from those of the other 14 strains examined. As a result, it was suggested that this outbreak of $S$. Typhimurium infection was caused by a clone that was distinct from other isolates in Hidaka Prefecture.

Another five strains isolated between 1990 and 1993 in Hidaka Prefecture demonstrated different drug resistance plasmid profiles, even though they were all the same biotype (biotype 1). It may, therefore, be suggested that these strains originated from different parental strains. Ishiguro et al. [9] isolated $S$. Typhimurium from various animals, including birds, in northern Japan and described all seven strains isolated from horses in 1976-1977 to be biotype 1. In contrast, McDonough et al. [12] described that biotype 1 was not a major biotype among horses in New York State during the period from 1973 until 1981. Considering this, it is suggested that biotype 1 may be one of the predominant biotypes in the horse population in Hokkaido of Japan.

It was demonstrated that eleven strains isolated from 1981 until 1996 harbored a virulence plasmid and were virulent in mice, while another five strains that did not contain a virulence plasmid, were not virulent in mice. Upon experimental infection, it was shown that strains virulent in mice were also virulent in foals. Thus, the virulence plasmid probably takes important role in $S$. Typhimurium infection of horses same as other domestic animals. In conclusion, it was suggested that large outbreaks of $S$. Typhimurium infection in foals are more likely to be caused by virulent strains harboring a virulence plasmid, although sporadic infections may also be caused by avirulent bacteria.

\section{Acknowledgments}

We are grateful to Hidaka and Sorachi Livestock Hygiene Service Centers for providing $S$. Typhimurium isolates. We also thank Ms. J. Goma, Ms. F. Yomogida and Mr. T. Yamakawa for their technical assistance.

\section{References}

1. Akiba, M., Sameshima, T., Anzai, T., Wada, R., and Nakazawa, M. 1999. Salmonella Abortusequi strains of equine origin harbor a $95 \mathrm{~kb}$ plasmid responsible for virulence in mice. Vet. Microbiol. 68: 265-272.

2. Birnboim, H.C. and Doly, J. 1979. A rapid alkaline extraction procedure for screening recombinant plasmid DNA. Nucleic Acids Res. 7: 1513-1523.

3. Duguid, J.P., Anderson, E.S., Alfredsson, G.A., Barker, R., and Old, D.C. 1975. A new biotyping scheme for Salmonella typhimurium and its phylogenetic significance. J. Med. Microbiol. 8: 149166.

4. van Duijkeren, E., van Klingeren, B., Vulto, A.G., Solet van Oldruitenborgh-Oosterbaan, M.M., Breukink, H.J., and van Miert, A.S.J.P.A.M. 1995. In vitro susceptibility to antimicrobial drugs of 62 Salmonella strains from horses in the Netherlands. Vet. Microbiol. 45: 19-26.

5. van Duijkeren, E., Solet van OldruitenborghOosterbaan, M.M., Houwers, D.J., van Leeuwen, W.J., and Kalsbeek, H.C. 1994. Equine salmonellosis in Dutch veterinary teaching hospital. Vet. Rec. 135: 248-250.

6. Hansen, L.M., Jang, S.S., and Hirsb, D.C. 1993. Use of random fragments of chromosomal DNA to highlight restriction site heterogeneity for finger printing isolates of Salmonella typhimurium from hospitalized animals. Am. J. Vet. Res. 54: 16481652.

7. House, J.K., Smith, B.P., Wildman, T.R., Carrigan, M.J., and Kamiya, D.Y. 1999. Isolation of Salmonella organisms from the mesenteric lymph nodes of horses at necropsy. J. Am. Vet. Med. Assoc. 215: 507510.

8. House, J.K., Mainar-Jaime, R.C., Smith, B.P., House, A., and Kamiya, D.Y. 1999. Risk factors for nosocomial Salmonella infection among hospitalized horses. J. Am. Vet. Med. Assoc. 214: 1511-1516.

9. Ishiguro, N. and Sato, G. 1981. Biotyping of Salmonella typhimurium strains isolated from animals and birds in northern Japan. Am. J. Vet. Res. 42: 896-897.

10. Kado, C.I. and Liu, S.T. 1981. Rapid procedure for detection and isolation of large and small plasmids. J. Bacteriol. 145: 1365-1373.

11. Kikuchi, N., Kawakami, Y., Murase, N., Ohishi, H., Tomioka, Y., Iwata, K., Fujimura, M., and Sakazaki, R. 1982. The isolation of Salmonella typhimurium from foals with pyrexia and diarrhea. Bull. Equine Res. Inst. 19: 43-50 (in Japanese with English summary).

12. McDonough, P.L., Timoney, J.F., Jacobson, R.H., and Khakhria, R. 1989. Clonal groups of Salmonella 
typhimurium in New York state. J. Clin. Microbiol. 27: 622-627.

13. Rabsch, W., Andrews, H.L., Kingsley, R.A., Prager, R., Tschape, H., Adams, L.G., and Baumler, A. J. 2002. Salmonella enterica serotype Typhimurium and its host-adapted variants. Infect. Immune. 70: 2249-2255.

14. Reed, L.J. and Muench, H. 1938. A simple method of estimating fifty per cent endpoints. Am. J. Hyg. 27, 493-497.

15. Rexach, L., Dilasser, F., and Fach, P. 1994. Polymerase chain reaction for salmonella virulence-associated plasmid genes detection: a new tool in salmonella epidemiology. Epidemiol. Infect. 112: 33-43.

16. Sato, G., Ishiguro, N., Asagi, M., Oka, C., Kawanishi, T., and Inoue, T. 1977. Biochemical characteristics and in vitro drug sensitivity of
Salmonella typhimurium, Copenhagen variety isolated from domestic and feral pigeons, crows, a kite, chickens and animals in Japan. Jpn. J. Vet. Sci. 39: 609-617.

17. Schott II, H.C., Ewart, S.L., Walker, R.D., Dwyer, R.M., Dietrich, S., Eberhart, S.W., Kusey, J., Stick, J.A., and Derksen, F.J. 2001. An outbreak of salmonellosis among horses at a veterinary teaching hospital. Am. J. Vet. Med. Assoc. 218: 11521159.

18. Spier, S.J. 1993. Salmonellosis. Vet. Clin. North Am.: Equine Prac. 9: 385-394.

19. Weese, J.S., Baird, J.D., Poppe, C., and Archambault, M. 2001. Emergence of Salmonella typhimurium definitive type 104 (DT104) as an important cause of salmonellosis in horses in Ontario. Can. Vet. J. 42: 788-792. 